\title{
GMR
}

\section{Suppression of the biological activity of neuroglioma cells by down-regulation of miR-1}

\author{
Y.Q. Wang*, Y. Cai* and X.M. Zhong \\ Department of Neurosurgery, The First People's Hospital of Huzhou, \\ The First Affiliated Hospital of Huzhou University, Huzhou, \\ Zhejiang Province, China \\ *These authors contributed equally to this study. \\ Corresponding author: X.M. Zhong \\ E-mail: weiwannhh@sina.com
}

Genet. Mol. Res. 16 (3): gmr16039256

Received September 12, 2016

Accepted January 13, 2017

Published August 31, 2017

DOI http://dx.doi.org/10.4238/gmr16039256

Copyright $(2017$ The Authors. This is an open-access article distributed under the terms of the Creative Commons Attribution ShareAlike (CC BY-SA) 4.0 License.

ABSTRACT. Neuroglioma is associated with high rates of malignancy,
metastasis, and recurrence. Recently, research on the roles of microRNAs
(miR) in cancer prognosis has formed an important area of research
as differential expression of miRNAs has been observed in different
cancers. However, the detailed mechanism by which miRNAs regulate
glioma remains unknown. Thus, we investigated the effect of miR-1
on human glioma by inhibiting the expression of miR-1. Anti-miR-1,
an anti-sense oligonucleotide against miR-1, significantly reduced the
level of miR-1 in the human glioma cell line U87 (P $<0.05)$. Further,
cell proliferation and colony formation assays were used to determine
the effect of miR-1 on cell growth. The scratch assay and cell migration
assay were performed to evaluate cell invasion. Our data demonstrated
that the growth of glioma cells was impeded due to the decrease in
miR-1 levels, compared to the untransfected control cells (P $<0.05)$.
Interestingly, the invasion and mobility of the cells were also retarded
after transfection with anti-miR-1 (P $<0.05)$. In conclusion, our results
indicate that the down-regulation of miR-1 significantly inhibited cell

Genetics and Molecular Research 16 (3): gmr16039256 
proliferation and reduced cell motility, suggesting that anti-miR-1 could be used as a therapeutic intervention tool to counter the activity of neuroglioma cells.

Key words: microRNA-1; Neuroglioma; Cell proliferation; Cell migration; Cell motility

\section{INTRODUCTION}

Neuroglioma is the most common sub-type of solid tumors and is ranked as the secondmost lethal solid tumor worldwide (Sarli and Giannis 2008, Xu et al., 2011, Marra et al., 2013). Symptoms of neuroglioma may be subtle and worsen gradually, or may it may present as an acute illness. Headaches are common, along with several cases of movement disorder, auditory and speech malfunction, and confused thinking (Lang et al., 1993). The exact mechanism of occurrence of neuroglioma remains unclear. Heredity, diet composition, electromagnetic radiation, and microbial infection are proposed as risk factors in the progression of the disease (Reuss and von Deimling 2009). The therapy for neuroglioma varies according to the location, cell type, and grade of the malignancy. Besides surgery, current treatment mainly focuses on chemotherapy and radiotherapy. Temozolomide, for instance, was shown to traverse the blood-brain barrier, and therefore, is currently being used to treat high-grade tumors (Morr et al., 2016). However, various side effects and adverse prognosis exist, such as the unhindered proliferation of tumor stem cells that aggravate recurrence, as well as metastasis to other solid organs such as lymph nodes after enhancement of cell motility (Liu et al., 2013).

With the advancement of molecular microbiology in recent years, various novel methods have been developed for the treatment of glioma. RNA interference (RNAi), for example, has been widely used to treat glioma on the genetic level (Judge et al., 2009; Yin et al., 2010; Deezagi et al., 2012). RNAi involves hybridization of the coding sequences with the non-sense small RNA fragments that causes targeted silencing of mRNA, and thereby, gene expression. RNAi has become an important subject in both basic research and clinical treatment (Peroukides et al., 2010; Sun et al., 2012), and RNAi-based treatment for glioma is currently a new research objective. As a muscle-specific miR, miR-1 is associated with heart development and arrhythmia/myocardial hypertrophy and is a potential therapeutic tool in medical research (Oh et al., 1999; Tai et al., 2012). A recent study demonstrated that high expression of $m i R-1$ was observed in esophageal squamous cell carcinoma (ESCC) tissues and cell lines. Cell proliferation, invasion, metastasis, and progression of ESCC were affected by targeting of LASP1 and TAGLN2 by miR-1 (Du et al., 2016). In contrast, in colorectal carcinoma (CRC) tissues and cell lines, the expression of $m i R-1$ was reduced, and miR-1 contributed to the restriction of CRC metastasis via the MAPK and PI3K/AKT pathway (Xu et al., 2014). These findings indicate that miR-1 plays a critical role in cancer progression and is a potential candidate for the molecular therapy of cancer. However, the exact function of miR1 in the occurrence and progression of neuroglioma is unknown. Additionally, microRNAs such as miR-181a can be down-regulated to activate caspase-3 expression in the treatment of neurological disorders (Ren et al., 2016). miR-133 can inhibit cell migration and invasion of the pituitary adenoma by directly targeting $F O X C 1$, implying that microRNAs are potential therapeutic targets for treatment of neurological diseases (Wang et al., 2016). In this study, we sought to investigate the role of miR-1 in the human neuroglioma U87 cell line.

Genetics and Molecular Research 16 (3): gmr16039256 
miR-1 and neuroglioma

\section{MATERIAL AND METHODS}

\section{Reagents}

Fetal bovine serum (FBS) was purchased from Hyclone (Logan, UT, USA). Opti Minimum Essential Medium (MEM) and Roswell Park Memorial Institute (RPMI) 1640 media were purchased from Gibco (Grand Island, NY, USA). Lipofectamine 2000 was from Invitrogen (Carlsbad, CA, USA). $0.5 \mathrm{~g}$ MTT was dissolved in $100 \mathrm{~mL}$ PBS, filtered through a $0.22-\mathrm{mm}$ membrane, and stored in the dark at $4^{\circ} \mathrm{C}$. The anti-miR-1 (miR-1 antisense oligonucleotide) and a nonspecific anti-miR control were purchased from GenePharma (Shanghai, China). miR-1 primers were synthesized by Sangon Biotech Co. Ltd. (Shanghai, China).

\section{Stable transfection of U87 cells with anti-miR-1}

U87 cells at log-phase of growth were seeded in 6-well plates (with $3 \times 10^{5}$ to $5 \times 10^{5}$ cells per well) without antibiotics for $24 \mathrm{~h}$ prior to transfection, resulting in $60-80 \%$ confluency. miRNAs were transfected at a working concentration of $100 \mathrm{nM}$ using Lipofectamine 2000 reagent according to the manufacturer's instructions. Anti-miR-1 (miR-1 inhibitor) was mixed with serum-free Opti MEM medium containing Lipofectamine 2000 according to the manufacturer's recommendation. After $6 \mathrm{~h}$ at $37^{\circ} \mathrm{C}$, the medium was changed, and the cells were cultured in RPMI 1640 supplemented with 10\% heat-inactivated FBS. After $48 \mathrm{~h}$, RNA was extracted for detecting the levels of miR-1. Cells transfected with the non-specific anti-miR-1 oligonucleotide served as a negative control (NC), whereas, untransfected cells were used as blank control.

\section{RNA extraction}

Total RNA was extracted and purified from cultured U87 cells by TaKaRa MiniBEST Universal RNA Extraction Kit (TaKaRa, Japan). The concentration and purity of RNA were measured by Nano Drop 2000 (Thermo Fisher Scientific, USA); a value of 1.9-2.0 of the ratio of the absorbance at $260 \mathrm{~nm}$ and $280 \mathrm{~nm}$ (A260/280) indicated highly pure RNA.

\section{Reverse transcription-polymerase chain reaction (RT-PCR)}

RT-PCR was performed in a $25-\mu \mathrm{L}$ reaction volume containing 2 mg RNA, $1 \mu \mathrm{L}$ oligo dT $(50 \mu \mathrm{M}), 2 \mu \mathrm{L}$ dNTP $(10 \mathrm{mM})$ and DEPC-treated water by using SuperScript ${ }^{\mathbb{R}}$ III One-Step RT-PCR System with Platinum ${ }^{\circledR}$ Taq (Thermo Fisher Scientific, Waltham, MA, USA). In vitro reverse transcription was initiated by denaturation at $65^{\circ} \mathrm{C}$ for $5 \mathrm{~min}$, followed by addition of 4 $\mu \mathrm{L}$ synthesis buffer (containing 5 x cDNA), $1 \mu \mathrm{L} 0.1 \mathrm{M}$ DTT, 40 units RNase Out, $1 \mu \mathrm{L}$ DEPCtreated water, reverse transcriptase $(0.5 \mu \mathrm{L})$ (ThermoScript, USA), and 15 units reaction buffer. The reverse transcription reaction was incubated at $50^{\circ} \mathrm{C}$ for $1 \mathrm{~h}$, followed by incubation at $85^{\circ} \mathrm{C}$ for $5 \mathrm{~min}$. RNaseH was added to inactivate the residual RNA for $20 \mathrm{~min}$ at $37^{\circ} \mathrm{C}$.

\section{Quantitative PCR (qPCR)}

The Master Mix (Superarray, USA) was used for qPCR in a $25 \mu \mathrm{L}$ volume containing $12.5 \mu \mathrm{L}$ SYBR Green Master Mix, $10.5 \mu \mathrm{L}$ double distilled water, $1 \mu \mathrm{L}$ template cDNA, and 1

Genetics and Molecular Research 16 (3): gmr16039256 
$\mu \mathrm{L}$ PCR primer $(10 \mu \mathrm{M})$. PCR conditions were: pre-denaturation at $95^{\circ} \mathrm{C}$ for $10 \mathrm{~min}$, followed by 40 cycles of denaturation at $95^{\circ} \mathrm{C}$ for $30 \mathrm{sec}$, annealing at $55^{\circ} \mathrm{C}$ for $30 \mathrm{sec}$, and elongation at $72^{\circ} \mathrm{C}$ for $30 \mathrm{sec}$. The melting curve analysis was used to determine the relative expression levels. The primer sequences were: $m i R-1-\mathrm{F}$ : 5'-GAGGAGGCTGGAGAA-3'; miR-1-R: 5'-GGTGGAATGTAAAGAAGTC-3'; GAPDH-F： 5'-AGAAGGCTGGGGCTCATTTG-3'; GAPDH-R: 5'-CTCGCTCCTGGAAGATGGTG-3'. GAPDH was used as an internal control.

\section{3-(4,5-dimethylthiazol-2-yl)-2,5-diphenyltetrazolium bromide (MTT) assay}

The U87 cells were prepared as single cell suspensions in culture medium containing $10 \%$ FBS, and were seeded on 96-well plates, with $0.2 \mathrm{~mL}$ culture in each well (containing $5000-6000$ cells). After the attachment and growth of the cells, the MTT solution $(5 \mathrm{mg} / \mathrm{mL}$ in PBS, $\mathrm{pH} 7.4)$ was added to each well $(20 \mu \mathrm{L})$. After $4 \mathrm{~h}$ of incubation, supernatants were discarded. Cells were recentrifuged and were mixed with $150 \mu \mathrm{L}$ dimethyl sulfoxide. The crystal was dissolved by vortexing for $10 \mathrm{~min}$. Absorbance at $490 \mathrm{~nm}$ was measured to plot the growth of cells as a function of time.

\section{Clonal formation assay}

Cell suspensions were seeded in culture dishes (about 100 cells) until they formed visible colonies. Supernatants were discarded by rinsing twice with PBS (pH 7.4). 4\% paraformaldehyde was added to fix the cells for $15 \mathrm{~min}$. The fixing buffer was then removed and crystal violet was added and incubated for 10-30 min. The excess dye was washed away under tap water and the plates were air-dried. The clonal formation assay reflected both the colony-dependency and proliferation features of the cells.

\section{Scratch assay}

The scratch assay was used to observe the motility of the tumor cells with attachment growth. Tubular epithelial cells (TEC) at log-phase was seeded in 6-well plates, with $3 \times 10^{5}$ to $5 \times 10^{5}$ cells per well. A sterilized tooth-stick was used to draw a "+" shape on the culture plate. Images were taken every $12 \mathrm{~h}$ for observing cell growth.

\section{Cell migration assay}

Neuroglioma cells were seeded in 6-well plates $(1 \mathrm{~mL}$ each). Four plates were used for each group. When the cells were $70 \%$ confluent, Lipofectamine 2000 was used to transfect 100 nmol anti-miR-1 or anti-miR NC. After $72 \mathrm{~h}$, the cells were digested by trypsin and were added into the upper chamber of the Trans-well, whose lower chamber was filled with Dulbecco's modified Eagle's medium (DMEM) containing 5\% FBS. After $24 \mathrm{~h}$ of incubation, the transwell chamber was washed, fixed, and stained by crystal violet. An inverted microscope (Olympus, Japan) was used to count the number of perforated cells in five different fields for calculating the average cell number in each field.

\section{Statistical analysis}

The SPSS 11.0 software package was used to process the collected data. The student's

Genetics and Molecular Research 16 (3): gmr16039256 
$t$-test was used to compare the means. Pearson analysis and the chi-square test were used to analyze correlations. A statistical significance was defined when $\mathrm{P}<0.05$.

\section{RESULTS}

\section{Down-regulation of miR-1 in glioma cells}

To construct a glioma cell line with down-regulated miR-1, U87 cells were transfected with anti-miR-1. qPCR (Figure 1) showed that the expression of miR-1 in the cells transfected with anti-miR-1 was significantly lowered $(4.3 \pm 1.5)$ than that in the NC group $(25.2 \pm 1.9)$ or blank control $(25.9 \pm 1.3)(\mathrm{P}<0.05)$, while no remarkable difference was observed between the $\mathrm{NC}$ and the blank control $(\mathrm{P}>0.05)$, suggesting that the reduced level of miR-1 in U87 cells was anti-miR-1 specific.

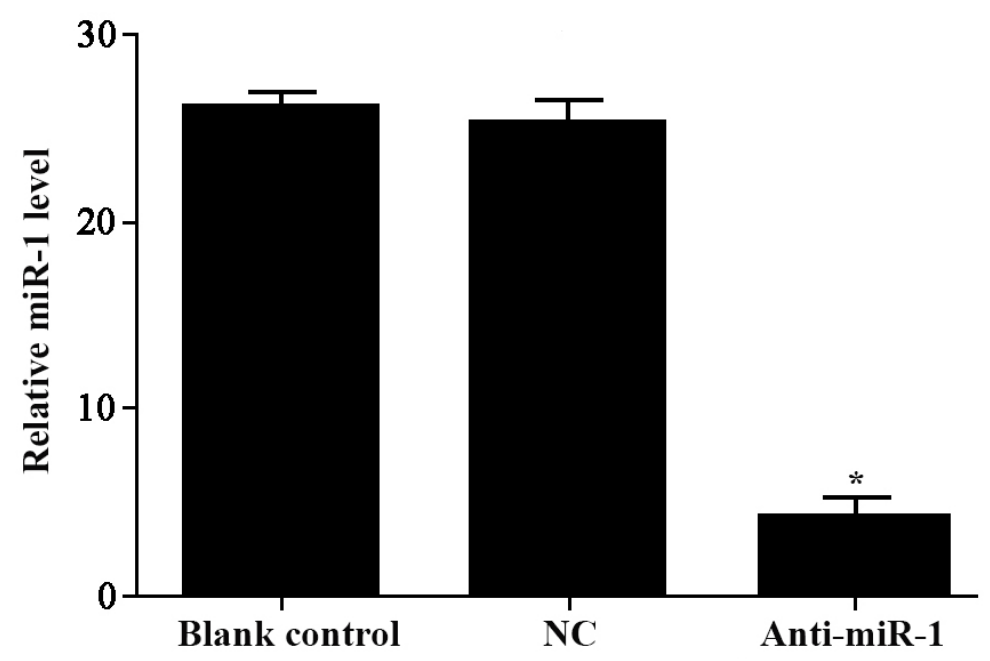

Figure 1. Expression of miR-1 analyzed by RT-PCR was decreased in glioma cells. Bar graph depicting the levels of miR-1 normalized by that of GAPDH. Data are reported as means \pm SD. $* \mathrm{P}<0.05$ compared with the blank control.

\section{Down-regulation of miR-1 inhibited the growth of glioma cells}

The MTT assay was used to detect the effect of miR-1 on cell growth at 24, 48, and 72 $\mathrm{h}$ after the transfection with anti-miR-1 or anti-miR NC. Results showed that the proliferation of the cells in the anti-miR-1 group was significantly inhibited $(0.31 \pm 0.11$ at $24 \mathrm{~h} ; 0.49 \pm$ 0.13 at $48 \mathrm{~h} ; 0.91 \pm 0.15$ at $72 \mathrm{~h})$ compared to that of the cells without any treatment $(\mathrm{P}<$ $0.05)$, whereas the proliferative abilities in the $\mathrm{NC}$ group $(1.08 \pm 0.16$ at $24 \mathrm{~h} ; 1.63 \pm 0.14$ at $48 \mathrm{~h} ; 2.69 \pm 0.18$ at $72 \mathrm{~h})$ or blank control $(1.05 \pm 0.13$ at $24 \mathrm{~h} ; 1.51 \pm 0.15$ at $48 \mathrm{~h} ; 2.43$ \pm 0.20 at $72 \mathrm{~h}$ ) were approximately similar (Figure $2 \mathrm{~A}$ ). This was further validated by the clonal formation assay, which demonstrated that the down-regulation of miR-1 suppressed cell growth compared to that in the blank or the negative control, indicating that miR-1 plays a positive role in the proliferation of the glioma cells (Figure 2B).

Genetics and Molecular Research 16 (3): gmr16039256 




B Blank control NC Anti-miR-1


Figure 2. Cell proliferation was inhibited by down-regulation of miR-1. A. Absorbance values at $490 \mathrm{~nm}$ were determined to evaluate cell growth after the MTT assay. ${ }^{*} \mathrm{P}<0.05$ compared with blank control. Each bar represents means $\pm \mathrm{SD} ; \mathbf{B}$. Images showing the results of the clonal formation assay. Blue dots indicated the cell colonies. All least three independent experiments were performed.

\section{Reducing the level of miR-1 impeded cell motility and migration}

We utilized the scratch assay to detect cell mobility and invasion at 0,12 , and $24 \mathrm{~h}$ post-transfection. Our data revealed an increase in the number of migrated cells in the NC group. However, the number of migrated cells was lower after treatment with anti-miR-1 (Figure 3A). At the same time, a parallel assay for detecting cell motility demonstrated that the migration was relatively retarded after the transfection with anti-miR-1 $72 \mathrm{~h}$ after the transfection, compared to that observed in the blank or negative control (Figure 3B). The data also showed that there was a statistical decrease in the number of migrated cells in anti-miR-1 group (11.2 \pm 1.8$)$, compared to that in the blank control $(22.5 \pm 2.6)(\mathrm{P}<0.05)$ (Figure 3C). Together, these results suggested that the invasiveness of the glioma cells was alleviated by the reduction in the level of miR-1. 



B

Blank control

$\mathrm{NC}$

Anti-miR-1

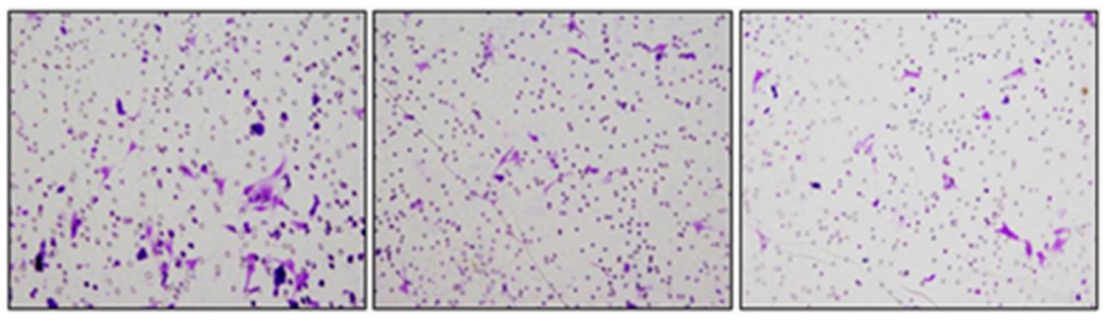

Figure 3. Effects of reduced miR-1 level on the migration and invasion of glioma cells. A. Invasion of cells was determined by the scratch assay; scratch healing was observed at $0,12,24 \mathrm{~h}$ post- transfection; $\mathbf{B}$. Cell migration was observed by the trans-well assay after $72 \mathrm{~h}$ of transfection; C. Histogram showing the average number of perforated cells in five fields. ${ }^{*} \mathrm{P}<0.05$ compared with the blank control. Data are represented as means $\pm \mathrm{SD}$. All least three independent experiments were performed.

\section{DISCUSSION}

The pathogenesis of neuroglioma, a highly malignant tumor, is complicated by the involvement of aberrant gene expression which affects cell growth, invasiveness, and motility. The hyperactive tumor cell motility is one of the main reasons for the aggravation of tumor growth. Recently, miRNAs have been shown to be involved in the proliferation, invasion, and apoptosis of various tumors, and the enhancement or suppression of tumor motility was influenced by the modulation of small RNA levels (Krol et al., 2010). For instance, miR-129 affected the proliferation of pulmonary carcinoma via the down-regulation of Cdk6 in a mouse lung cancer cell line (Cheng et al., 2005). Studies have demonstrated that tumor cell growth and motility, as well as infiltration of neuroglioma, are closely related to tumor metastasis (Chen et al., 2006; Atkinson et al., 2010). However, the exact roles of microRNAs in the aggravation of tumor cell mobilization are still unknown.

Previous studies have found that microRNAs could inhibit intestinal tumor cell growth and elevate levels of apoptosis, suggesting that the effective inhibition of tumor cell growth by targeted microRNAs can be considered for treatment of tumors (Ikeda et al., 2007; Mangoni and Nargeot, 2008). Several findings reported that miRNAs accelerated the invasiveness of neuroglioma, while others demonstrated an opposite role of miRNAs in the

Genetics and Molecular Research 16 (3): gmr16039256 
inhibition of cancer migration and invasiveness (Yang et al., 2007). For example, miR-146b can inhibit migration and invasion of the neuroglioma cells (Buck et al., 1999), and miR133 suppressed cell migration and invasion of the pituitary adenoma (Wang et al., 2016). In contrast, miR-125b enhanced skin tumor and prolonged malignant cell survival (Zhang et al., 2014). Moreover, miR-29a regulated the heat shock protein 47 to enhance glioma tumor growth and invasion (Zhao et al., 2014).

Neuroglioma is the leading cause of intracranial tumor. As a small molecule RNA present in muscles, miR-1 has been sparsely studied in neuroglioma cells. As previous studies indicated that the expression of miR-1 was higher in neuroglioma cells compared to that in normal cells (Cao et al., 2012), we investigated whether the suppression of miR-1 could affect the proliferation of the glioma cells. We down-regulated the level of miR-1 in the human neuroglioma cell U87 by transfection with anti-miR-1. Notably, reducing the level of miR1 impeded cell proliferation and retarded colony formation. Additionally, the lowering of miR-1 expression inhibited the invasiveness and motility of the tumor cells. Overexpression of miRNAs, such as miR-200c, miR-141, miR-126, and miR-132, suppressed glioma cell growth and migration (Guo et al., 2016; Li et al., 2016; Wang et al., 2015). Interestingly, our result demonstrated that reducing the expression of miR-1 had a similar inhibitory role in the glioma cells, which is consistent with a previous finding that shows that the alleviation of $m i R$ 1 expression inhibited colorectal carcinoma metastasis. This indicates that the progression of specific cancers may be restricted by anti-miR-1 (Xu et al., 2014). However, in vivo experiments are required to confirm the tumor-suppressive effects of anti-miR-1, identify its potential downstream targets, and understand its molecular mechanisms of action.

Taken together, our preliminary data highlighted the role of miR-1 in the metastasis of glioma cells and provided a potential therapeutic target for the treatment of high-grade glioma.

\section{Conflicts of interest}

The authors declare no conflict of interest.

\section{ACKNOWLEDGMENTS}

We thank the anonymous reviewers for reviewing this manuscript.

\section{REFERENCES}

Atkinson GP, Nozell SE and Benveniste ET (2010). NF-kappaB and STAT3 signaling in glioma: targets for future therapies. Expert Rev. Neurother. 10: 575-586. http://dx.doi.org/10.1586/ern.10.21

Buck M, Poli V, van der Geer P, Chojkier M, et al. (1999). Phosphorylation of rat serine 105 or mouse threonine 217 in C/EBP beta is required for hepatocyte proliferation induced by TGF alpha. Mol. Cell 4: 1087-1092. http://dx.doi. org/10.1016/S1097-2765(00)80237-3

Cao J, Shen Y, Zhu L, Xu Y, et al. (2012). miR-129-3p controls cilia assembly by regulating CP110 and actin dynamics. Nat. Cell Biol. 14: 697-706. http://dx.doi.org/10.1038/ncb2512

Chen JF, Mandel EM, Thomson JM, Wu Q, et al. (2006). The role of microRNA-1 and microRNA-133 in skeletal muscle proliferation and differentiation. Nat. Genet. 38: 228-233. http://dx.doi.org/10.1038/ng1725

Cheng AM, Byrom MW, Shelton J and Ford LP (2005). Antisense inhibition of human miRNAs and indications for an involvement of miRNA in cell growth and apoptosis. Nucleic Acids Res. 33: 1290-1297. http://dx.doi.org/10.1093/ $\underline{\text { nar/gki200 }}$

Deezagi A, Ansari-Majd S and Vaseli-Hagh N (2012). Induced apoptosis in human prostate cancer cells by blocking of

Genetics and Molecular Research 16 (3): gmr16039256 
vascular endothelial growth factor by siRNA. Clin. Transl. Oncol. 14: 791-799. http://dx.doi.org/10.1007/s12094$\underline{012-0868-1}$

Du YY, Zhao LM, Chen L, Sang MX, et al. (2016). The tumor-suppressive function of miR-1 by targeting LASP1 and TAGLN2 in esophageal squamous cell carcinoma. J. Gastroenterol. Hepatol. 31: 384-393. http://dx.doi.org/10.1111/ igh. 13180

Guo E, Wang Z and Wang S (2016). MiR-200c and miR-141 inhibit ZEB1 synergistically and suppress glioma cell growth and migration. Eur. Rev. Med. Pharmacol. Sci. 20: 3385-3391.

Ikeda S, Kong SW, Lu J, Bisping E, et al. (2007). Altered microRNA expression in human heart disease. Physiol. Genomics 31: 367-373. http://dx.doi.org/10.1152/physiolgenomics.00144.2007

Judge AD, Robbins M, Tavakoli I, Levi J, et al. (2009). Confirming the RNAi-mediated mechanism of action of siRNAbased cancer therapeutics in mice. J. Clin. Invest. 119: 661-673. http://dx.doi.org/10.1172/JCI37515

Krol J, Loedige I and Filipowicz W (2010). The widespread regulation of microRNA biogenesis, function and decay. Nat. Rev. Genet. 11: 597-610.

Lang FF, Epstein FJ, Ransohoff J, Allen JC, et al. (1993). Central nervous system gangliogliomas. Part 2: Clinical outcome. J. Neurosurg. 79: 867-873. http://dx.doi.org/10.3171/jns.1993.79.6.0867

Li Y, Li Y, Ge P and Ma C (2016). MiR-126 regulates the ERK pathway via targeting KRAS to inhibit the glioma cell proliferation and invasion. Mol. Neurobiol. 54: 137-145.

Liu X, Gong H and Huang K (2013). Oncogenic role of kinesin proteins and targeting kinesin therapy. Cancer Sci. 104: 651-656. http://dx.doi.org/10.1111/cas.12138

Mangoni ME and Nargeot J (2008). Genesis and regulation of the heart automaticity. Physiol. Rev. 88: 919-982. http:// dx.doi.org/10.1152/physrev.00018.2007

Marra E, Palombo F, Ciliberto G and Aurisicchio L (2013). Kinesin spindle protein SiRNA slows tumor progression. $J$. Cell. Physiol. 228: 58-64. http://dx.doi.org/10.1002/jep.24103

Morr S, Qiu J, Prasad D, Mechtler LL, et al. (2016). Radiologic response to radiation therapy concurrent with temozolomide for progressive simple dysembryoplastic neuroepithelial tumor. Acta Neurochir. (Wien) 158: 1363-1366. http:// dx.doi.org/10.1007/s00701-016-2832-2

Oh H, Takagi H, Suzuma K, Otani A, et al. (1999). Hypoxia and vascular endothelial growth factor selectively upregulate angiopoietin-2 in bovine microvascular endothelial cells. J. Biol. Chem. 274: 15732-15739. http://dx.doi. org/10.1074/jbc.274.22.15732

Peroukides S, Bravou V, Alexopoulos A, Varakis J, et al. (2010). Survivin overexpression in HCC and liver cirrhosis differentially correlates with p-STAT3 and E-cadherin. Histol. Histopathol. 25: 299-307.

Ren L, Zhu R and Li X (2016). Silencing miR-181a produces neuroprotection against hippocampus neuron cell apoptosis post-status epilepticus in a rat model and in children with temporal lobe epilepsy. Genet. Mol. Res. 15: 15017798. http://dx.doi.org/10.4238/gmr.15017798

Reuss D and von Deimling A (2009). Hereditary tumor syndromes and gliomas. Recent Results Cancer Res. 171: 83-102. http://dx.doi.org/10.1007/978-3-540-31206-2_5

Sarli V and Giannis A (2008). Targeting the kinesin spindle protein: basic principles and clinical implications. Clin. Cancer Res. 14: 7583-7587. http://dx.doi.org/10.1158/1078-0432.CCR-08-0120

Sun P, Yu H, Zhang WQ, Hu M, et al. (2012). Lentivirus-mediated siRNA targeting VEGF inhibits gastric cancer growth in vivo. Oncol. Rep. 28: 1687-1692.

Tai J, Wang G, Liu T, Wang L, et al. (2012). Effects of siRNA targeting c-Myc and VEGF on human colorectal cancer Volo cells. J. Biochem. Mol. Toxicol. 26: 499-505. http://dx.doi.org/10.1002/jbt.21455

Wang DS, Zhang HQ, Zhang B, Yuan ZB, et al. (2016). miR-133 inhibits pituitary tumor cell migration and invasion via down-regulating FOXC1 expression. Genet. Mol. Res. 15: 15017453. http://dx.doi.org/10.4238/gmr.15017453

Wang H, Li XT, Wu C, Wu ZW, et al. (2015). miR-132 can inhibit glioma cells invasion and migration by target MMP16 in vitro. Onco Targets Ther. 8: 3211-3218.

$\mathrm{Xu} \mathrm{C}$, Lee SA and Chen X (2011). RNA interference as therapeutics for hepatocellular carcinoma. Recent Patents Anticancer. Drug Discov. 6: 106-115. http://dx.doi.org/10.2174/157489211793980097

Xu L, Zhang Y, Wang H, Zhang G, et al. (2014). Tumor suppressor miR-1 restrains epithelial-mesenchymal transition and metastasis of colorectal carcinoma via the MAPK and PI3K/AKT pathway. J. Transl. Med. 12: 244. http://dx.doi. org/10.1186/s12967-014-0244-8

Yang B, Lin H, Xiao J, Lu Y, et al. (2007). The muscle-specific microRNA miR-1 regulates cardiac arrhythmogenic potential by targeting GJA1 and KCNJ2. Nat. Med. 13: 486-491. http://dx.doi.org/10.1038/nm1569

Yin Y, Cao LY, Wu WQ, Li H, et al. (2010). Blocking effects of siRNA on VEGF expression in human colorectal cancer cells. World J. Gastroenterol. 16: 1086-1092. http://dx.doi.org/10.3748/wjg.v16.i9.1086

Genetics and Molecular Research 16 (3): gmr16039256 
Zhang L, Ge Y and Fuchs E (2014). miR-125b can enhance skin tumor initiation and promote malignant progression by repressing differentiation and prolonging cell survival. Genes Dev. 28: 2532-2546. http://dx.doi.org/10.1101/ gad.248377.114

Zhao D, Jiang X, Yao C, Zhang L, et al. (2014). Heat shock protein 47 regulated by miR-29a to enhance glioma tumor growth and invasion. J. Neurooncol. 118: 39-47. http://dx.doi.org/10.1007/s11060-014-1412-7

Genetics and Molecular Research 16 (3): gmr16039256 